\title{
Factors Associated with Attendance and Non-Attendance of Support Groups among HIV Positive Adults Attending an Antiretroviral Community Clinic at Ekurhuleni District, South Africa
}

\author{
Sphiwe Madiba, Olga Kekana \\ School of Public Health, University of Limpopo, Medunsa Campus, Pretoria, South Africa. \\ Email: Sphiwe_madiba@embanet.com
}

Received February $28^{\text {th }}, 2013$; revised March $30^{\text {th }}, 2013$; accepted April $8^{\text {th }}, 2013$

Copyright (c) 2013 Sphiwe Madiba, Olga Kekana. This is an open access article distributed under the Creative Commons Attribution License, which permits unrestricted use, distribution, and reproduction in any medium, provided the original work is properly cited.

\begin{abstract}
Health care facilities providing antiretroviral treatment (ART) to HIV positive people have seen a decline in the uptake and use of HIV support groups. A cross sectional survey was conducted to 1) determine the characteristics of HIV positive people who have and who have not attended support groups; 2) determine factors associated with attendance of support groups; and 3) investigate perceived barriers to participate in support groups among HIV positive adults attending an ART clinic in Gauteng, South Africa. The total samples included 248 HIV positive adults and the highest proportion were females $(n=156,62.9 \%)$. The mean age of the participants was 34.2 years, (range 18 to 56 years). Almost two thirds $(\mathrm{n}=144,58.1 \%)$ had never attended support groups. Participants who attended support groups were more likely to be older than non-attenders ( $\mathrm{OR}=1.04$, CI: $1.01-1.07)$, more likely to be taking ART medication $(\mathrm{OR}=1.64$, CI: 1.00 - 2.65) and more likely to have known of their HIV diagnosis for a longer time (OR = 2.20, CI: $1.42-3.40)$. Employed participants were less likely to attend support groups than unemployed participants $(\mathrm{OR}=0.47$, CI: 0.27 0.80 ). Concerns for privacy and confidentiality in support groups, and fear of stigma and discrimination were the key barriers to participate in support groups. Participants also perceived support groups as a service for people who could not cope with their HIV diagnosis. Health care providers who plan to start support groups should take into consideration issues of support group size, confidentiality, and timing for support group meetings. It is imperative that education on the benefits of HIV support groups forms a primary component of routine counselling for PLWHI.
\end{abstract}

Keywords: South Africa; Disclosure, PLWHI; Support Groups; Participation; Barriers; ART

\section{Introduction}

Support groups were formed to provide care and support to people infected and affected by HIV and AIDS. People living with HIV (PLWHI) experience lower levels of social support after an HIV diagnosis than before the diagnosis [1]. Support groups are the most common psychosocial support services available to PLWHI. They have been used as a key intervention to help PLWHI in dealing with the changes that come with an HIV diagnosis for over three decades [2,3]. They also address the on-going psychological and social problems of PLWHI, their partners, families, and caregivers [4]. Support groups enhance the quality of life, decrease social isolation, create a sense of belonging, offer a forum of peer support, and offer an opportunity to learn from others who are facing similar challenges [1,5]. Furthermore, they provide PLWHI with a safe environment to talk about the disease, neutralize stigma, and allow members to practice new behaviors [2,6-8].

Participants of support groups benefit from obtaining information on new treatments and obtaining answers to questions about their disease [2,9]. The interaction with other HIV positive people is an essential component in the success of support groups and creates a sense of belonging among mutually empathetic members [5,6]. Participation in support groups also offers benefits of improved adherence to medication, decreased risk behavior for reinfection such as safer sex practices, condom use, and HIV status disclosure $[9,10]$. Few studies had compared support group attenders and non-attenders to assess the impact of non- 
attendance of HIV support groups on PLWHI. Kalichman and Sikkema [2] found that people who had not attended support groups reported more emotional distress, more avoidant coping, lower self-esteem, higher loneliness, and somatic depression than those who did attend.

Although support groups may be meeting the needs of PLWHI, some participants view them negatively and report various barriers that hinder participation [2]. There is evidence of poor participation in support groups by PLWHI from qualitative and quantitative data. Several studies have shown that HIV positive men are particularly reluctant to attend support groups and that in most mixed gender HIV support groups, women outnumber men [5,6, 11,12]. The poor participation of men in support groups might be attributed to the poor involvement of men in HIV prevention, care, and support programmes $[11,13]$. An additional reason for the low participation of men in support groups is the reluctance to disclose their HIV status in public. Disclosure of HIV status is inevitable in HIV support groups, and people who are not ready to disclose may fear participation for this reason [14].

Several studies documented various barriers to participate in support groups for PLWHI. Perceived barriers to HIV support group participation include perceptions that attendance implies an inability to cope, perceptions of adequate support from family, and perceptions of support groups as depressing [15]. Access and availability of support groups in local communities are also related to barriers for participation. Issues of appropriateness of support group venues, lack of transport money to attend support group meetings, work, and lack of time to attend meetings, were reported barriers to participate in support groups [8,16-18]. Other reasons for nonparticipation are; the large size of support groups, concerns about confidentiality and disclosure, personal disinclination, stigma and discrimination [16,19].

Although literature shows that support groups are a useful, effective, helpful, and supportive intervention for PLWHI [3], they are not viewed equally among PLWHI [2]. Early in the HIV epidemic in South Africa, support groups were widely available and utilized by PLWHI. However, recently, many health care facilities providing HIV care and support to PLWHI have seen poor uptake and use of support groups by PLWHI. This is despite reports that support groups are commonly advocated as the psychosocial support intervention for newly diagnosed HIV positive people as well as PLWHI. Taking into consideration that disclosure of HIV status is inevitable in support groups; individuals may fear social rejection and discrimination [14]. Stigma remains a significant concern within the health care service field across societies and limits the potential value of HIV treatment care and support $[20,21]$.
The poor participation of PLWHI in support groups is a major concern for health care providers in South Africa, where HIV counselling and testing are extensively promoted. Testing for HIV is the first step in the reduction of HIV transmission, and support groups assist PLWHI to obtain HIV-related information to develop strategies to change behavior. The poor uptake of support groups suggests that newly diagnosed HIV positive people lack psychosocial support. This is of much concern given the high level of HIV related stigma and discrimination in most communities in South Africa. Understanding the profile of people who seek HCT and barriers to attend support groups is crucial to inform the development of responsive psychosocial interventions for PLWHI. The study sought to 1) determine the characteristics of HIV positive people who have and who have not attended support groups; 2) determine factors associated with attendance of support groups; and 3) investigate perceived barriers to participate in support groups among HIV positive adults attending an ART clinic in Gauteng, South Africa.

\section{Methods and Materials}

\subsection{Study Design}

A cross sectional quantitative study was conducted among HIV infected adults attending an ART clinic in Gauteng province, South Africa, from November to December 2010. The study site, a community health centre, provides services to adult HIV infected people from an urban township and informal settlements in one of the largest districts in Gauteng Province, South Africa. The study participants were adult HIV infected men and women aged from 18 years and above who had tested positive at least six months prior to the survey. Participants were randomly selected from the wellness clinic which provides care and support to patients on prophylaxis as well as from the ART program.

\subsection{Data Collection}

Data were collected by the second author and research assistant. The research assistant was trained in the methods, objectives, and other logistics of the study before data collection commenced. Data were collected using a self-administered structured questionnaire. The questionnaire was adapted from previous studies as well as from inputs from literature on HIV support groups [2,22]. The questionnaire was first prepared in English and then translated into Setswana and IsiZulu, the local languages of participants in the study area. Pre-testing of the questionnaire was conducted in the study facility with 20 participants who were not included in the main study. The questionnaire captured demographic measures, HIV re- 
lated measures and HIV disclosure history. The demographic measures captured participant's age, gender, marital status, highest level of education attained, and employment status. HIV-related measures included; length of time since HIV diagnosis, ART status, (HIV positive, not on treatment, HIV positive on prophylaxis treatment and HIV positive on ART), current and previous attendance of HIV support groups, and barriers to attend support groups. HIV disclosure history was assessed by asking participants whether they had ever disclosed their HIV status to anyone and to whom they had disclosed their status.

\subsection{Ethics}

The Medunsa Research Ethics Committee of the University of Limpopo granted ethical approval for the study. The regional manager from the Ekurhuleni district and the facility manager of the Community Health Centre gave permission to conduct the study. Participants were informed of the confidential nature of the study, that participation was voluntary, and refusal to participate would not bring any undesirable consequences in terms of the ART service they received from the clinic. The participants were also assured about the right to withdraw from the study at any time. Written informed consent was obtained from each participant before data collection. No personal identifiers were collected from the participants to ensure participants confidentiality.

\subsection{Data Analysis}

Data were edited, cleaned, coded, and analysed using Stata 10.0 for Windows [23]. Descriptive statistics were calculated to explore the socio-demographic characteristics of participants who attended and those who did not attend support groups. Bivariate analysis was employed to test for statistically significant association between sociodemographic variables and attendance of HIV support groups. To identify independent associated factors, we conducted multivariate logistic regression analysis and all variables which were significant at bivariate analysis were simultaneously entered into the model. All analyses were conducted using logistic regressions, reporting odds ratios with 95\% confidence intervals.

\section{Results}

\subsection{Socio Demographic and Health Characteristics of the Participants}

The total sample included 248 HIV positive adults attending an ART clinic and the highest proportion ( $\mathrm{n}=$ 156, 62.9\%) were female. Participants were aged between 18 to 56 years, and the mean age was 34.2, (SD =
8.2 years), and a large percentage of the participants $(\mathrm{n}=$ 98, 39.7\%) were aged between 31 - 40 years. Slightly more than half $(\mathrm{n}=129,52 \%)$ had completed secondary school, more than half $(\mathrm{n}=130,52.6 \%)$ were single, a quarter $(\mathrm{n}=61,24.7 \%)$ were married, and the rest were separated, divorced, or widowed. Over half $(\mathrm{n}=149$, $60.3 \%$ ) were unemployed. With regard to time since diagnosis, half ( $\mathrm{n}=127,51.6 \%)$ had known of their HIV diagnosis for 1 - 5 years, more than a third $(n=91,37 \%)$ for less than a year, and a tenth $(n=23,9.4 \%)$ for $6-10$ years. Almost half $(\mathrm{n}=117,47.8 \%)$ were receiving ART medication, $(n=104,42.5 \%)$ were receiving prophylaxis medication, while less than a tenth $(n=24,9.8 \%)$ were not receiving any medication (Table $\mathbf{1}$ ).

Table 1. Demographic and health characteristics of HIV support group attenders and non-attenders by gender distribution.

\begin{tabular}{|c|c|c|c|c|}
\hline Characteristics & All $(n=248)$ & Male $(\mathrm{n}=92)$ & male $(n=156)$ & $\mathrm{p}$ value \\
\hline & & Age category & & \\
\hline 18 - 30 years & 94 (38.1) & 25 (26.6) & $69(73.4)$ & 0.014 \\
\hline 31 - 40 years & 98 (39.7) & 38 (38.8) & $60(61.2)$ & \\
\hline 41 - 50 years & 47 (19.0) & $24(51.1)$ & 23 (48.9) & \\
\hline 51 - 60 years & $8(3.2)$ & $5(62.5)$ & $3(37.5)$ & \\
\hline & & Iarital Status & & \\
\hline Single & 130 (52.6) & $43(46.7)$ & 87 (56.1) & 0.257 \\
\hline Married & $61(24.7)$ & $29(31.5)$ & 32 (20.7) & \\
\hline Separated & $17(6.9)$ & $8(8.7)$ & $9(5.8)$ & \\
\hline Divorced & $15(6.1)$ & $4(4.4)$ & $11(7.1)$ & \\
\hline Widowed & $24(9.7)$ & $8(8.7)$ & $16(10.3)$ & \\
\hline & Educ & ational attainm & & \\
\hline No schooling & $11(4.4)$ & $7(7.6)$ & $4(2.6)$ & 0.018 \\
\hline Primary & 76 (30.7) & $35(38.0)$ & $41(26.3)$ & \\
\hline Secondary & $129(52.0)$ & $37(40.2)$ & $92(59.0)$ & \\
\hline Tertiary & 32 (12.9) & $13(14.1)$ & $19(12.2)$ & \\
\hline & $E m$ & ployment statu. & & \\
\hline Unemployed & 98 (39.7) & 49 (53.9) & 49 (31.4) & 0.001 \\
\hline Employed & 149 (60.3) & $42(46.2)$ & 107 (68.6) & \\
\hline & Disclosure & of HIV status & others & \\
\hline Not disclosed & $22(8.9)$ & $8(8.7)$ & $14(9.0)$ & 0.941 \\
\hline Disclosed & 226 (91.1) & 84 (91.3) & $142(91.0)$ & \\
\hline & Attend & ing support gr & & \\
\hline Not attending & $144(58.1)$ & $46(50.0)$ & $98(62.8)$ & 0.048 \\
\hline Attending & 104 (41.9) & $46(50.0)$ & $58(37.2)$ & \\
\hline & & HIV staging & & \\
\hline No treatment & $24(9.8)$ & $2(2.2)$ & $22(14.9)$ & 0.008 \\
\hline Prophylaxis & $104(42.5)$ & 39 (43.3.5) & 65 (41.95) & \\
\hline ART & 117 (47.8) & $49(54.4)$ & 68 (43.9) & \\
\hline & Tim & e since diagnos & & \\
\hline$>1$ year & $91(37.0)$ & 30 (32.6) & 61 (39.6) & 0.402 \\
\hline 1 - 5 years & 127 (51.6) & $48(52.2)$ & 79 (51.3) & \\
\hline $6-10$ years & $23(9.4)$ & 12 (13.4) & $11(7.1)$ & \\
\hline$<10$ years & $5(2.0)$ & $2(2.2)$ & $3(2.0)$ & \\
\hline
\end{tabular}




\subsection{Disclosure of HIV Positive Status to Others}

With regard to disclosure of HIV status, 91\% $(n=226)$ disclosed their HIV status to other people, a third 29.8\% $(n=74)$ of the participants disclosed to partners and friends respectively, while almost a quarter $21.4 \%$ ( $\mathrm{n}=$ 53) disclosed to parents. Women disclosed to a greater degree $62.8 \%(\mathrm{n}=142)$ than men $37.2 \%(\mathrm{n}=84)$, although this difference was not statistically significant $\mathrm{x}^{2}$ $=0.005, \mathrm{p}=0.941$ (Table 2).

\subsection{Factors Associated with Attending HIV Support Groups}

More than half $58.1 \%(n=144)$ of the participants had never attended support groups while $41.9 \%(\mathrm{n}=104)$ reported previous HIV support group participation. The mean age of participants who attended support groups was 35.8 years, $(\mathrm{SD}=7.8$ years), CI: $34.3-37.3$, the mean age of participants who did not attend support groups was 33.0 years, $(\mathrm{SD}=8.39)$, CI: 31.6 - 34.4. Of the participants who reported previous support group attendance, half 50\% ( $\mathrm{n}=52)$ attended 1 - 2 support group meetings, slightly less than a quarter $23.1 \%(n=24)$ attended HIV support groups regularly for several weeks, only $1.9 \%(\mathrm{n}=2)$ attended HIV support groups regularly for one year or more. Among participants who attended at least one support group meeting, women attended support groups to a greater degree than men, $55.8 \%(n=58)$, this difference was statistically significant $\mathrm{x}^{2}=3.74, \mathrm{p}=$ 0.053 .

\section{Multivariate Model}

Multivariate logistic regression with attending a support group or not attending a support group entered as dependent variables and predictors entered simultaneously

Table 2. Disclosure of HIV positive status to others among HIV support group attenders and non-attenders.

\begin{tabular}{lcc}
\hline \multicolumn{1}{c}{ Disclose to } & $\mathrm{n}$ & $\%$ \\
\hline Not disclosed HIV status to anyone & 22 & 8.9 \\
Parents & 53 & 21.4 \\
Partner & 74 & 29.8 \\
Friends & 74 & 29.8 \\
Work colleague & 10 & 4.0 \\
Parent and partner & 6 & 2.4 \\
Parent, partner and friend & 4 & 1.6 \\
Friend and partner & 3 & 1.2 \\
Parents and friend & 2 & 0.8 \\
\hline
\end{tabular}

showed that ART status, time since diagnosis, employment status, and age remained significant when simultaneously entered into the model. Participants who attended support groups were 1.6 times more likely to be taking ART medication than non-attenders $(\mathrm{OR}=1.64$, CI: $1.00-2.65, \mathrm{p}=0.048$ ), but when we compared the groups by ART status, we found that the group receiving prophylaxis (OR $=1.08, \mathrm{CI}: 0.43-2.73$ ) was 1.08 times more likely to attend support groups that the group on ART $(\mathrm{OR}=0.76$, CI: $0.30-1.89)$. Participants who attended support groups were 2.2 times more likely to have known of their HIV diagnosis for a longer time than non-attenders (OR $=2.20$, CI: $1.42-3.40, \mathrm{p}<0.000)$. Employed participants were 53\% less likely to attend support groups than unemployed participants $(\mathrm{OR}=0.47$, CI: $0.27-0.80, p=0.004)$. Participants who attended support groups were more likely to be older $(\mathrm{OR}=1.04$, CI: 1.01- $1.07, \mathrm{p}=0.009)$, when we compared participants in the 41-50 years age group (OR $=2.74, \mathrm{CI} ; 1.30$ 5.77, $\mathrm{p}=0.005)$, and participants in the 31 - 40 years age group (OR $=1.58$, CI: $0.87-2.87, \mathrm{p}=0.121$ ) participants in the 41 - 50 years age group were 2.7 times more likely to attend support groups. When age was dichotomized to $>40$ years age group and $<40$ years age group, the $>40$ years age group were 1.7 times more likely to attend support groups than participants $<40$ years $(\mathrm{OR}=1.77$, CI: $0.96-3.27, p=0.06)$. Gender, level of education, marital status, and disclosure were not statistically associated with support group attendance (Table 3).

\subsection{Barriers to Participate in Support Groups}

Participants reported several perceived barriers to seeking support and attending HIV support groups. All participants responded to a question on why they were not attending support groups. The most common barriers indicated by the participants were concerns about privacy in HIV support groups, not wanting people to know about their HIV positive status, and the belief that they did not need support groups (Table 4).

\section{Discussion}

Factors that were statistically associated with support group attendance were the age of the participants, employment status, time since diagnosis with HIV, and ART status. Age was significantly associated with HIV support groups attendance; we found that participants older than 40 years were more likely to attend support groups than participants younger than 40 years. This finding is unique to this study as earlier studies did not find this association $[2,22]$.

Similar to previous studies, participants who attended HIV support groups have known about their HIV status 
Table 3. Demographic and health characteristics of HIV support group attenders and non-attenders.

\begin{tabular}{|c|c|c|c|c|}
\hline Characteristics & $\begin{array}{l}\text { Support group } \\
\text { non attendees } \\
(n=144) n \%\end{array}$ & $\begin{array}{l}\text { Support group } \\
\text { attendees } \\
(n=104) n \%\end{array}$ & $\begin{array}{c}\text { OR } \\
(95 \% \mathrm{CI})\end{array}$ & p-value \\
\hline \multicolumn{5}{|c|}{ Gender } \\
\hline Male & 46 (31.9) & $46(44.2)$ & $\begin{array}{c}0.86 \\
(0.46-1.58)\end{array}$ & 0.634 \\
\hline Female & $98(68.1)$ & 58 (55.8) & & \\
\hline \multicolumn{5}{|c|}{ Age category } \\
\hline 18 - 30 years & $63(43.8)$ & $31(30.1)$ & $\begin{array}{c}1.26 \\
(0.86-1.85)\end{array}$ & 0.219 \\
\hline 31 - 40 years & $55(38.2)$ & $43(41.8)$ & & \\
\hline 41 - 50 years & 20 (13.9) & $27(26.2)$ & & \\
\hline 51 - 60 years & $6(4.2)$ & $2(1.9)$ & & \\
\hline \multicolumn{5}{|c|}{ Employment status } \\
\hline Unemployed & $46(32.2)$ & $52(50.0)$ & $\begin{array}{c}0.46 \\
(0.25-0.84)\end{array}$ & 0.012 \\
\hline Employed & $97(67.8)$ & $52(50.0)$ & & \\
\hline \multicolumn{5}{|c|}{ Educational attainment } \\
\hline No schooling & $7(4.9)$ & $4(3.9)$ & $\begin{array}{c}0.95 \\
(0.62-1.45)\end{array}$ & 0.831 \\
\hline Primary & $38(26.4)$ & 38 (36.5) & & \\
\hline Secondary & $80(55.6)$ & $49(47.1)$ & & \\
\hline Tertiary & $19(13.2)$ & $13(12.5)$ & & \\
\hline \multicolumn{5}{|c|}{ Marital status } \\
\hline Single & $85(59.4)$ & $45(43.3)$ & $\begin{array}{c}1.07 \\
(0.83-1.39)\end{array}$ & 0.579 \\
\hline Married & $28(19.6)$ & $33(31.7)$ & & \\
\hline Separated & $10(7.0)$ & $7(6.7)$ & & \\
\hline Divorced & $8(5.6)$ & $7(6.7)$ & & \\
\hline Widowed & $12(8.4)$ & $12(11.5)$ & & \\
\hline \multicolumn{5}{|c|}{ HIV staging } \\
\hline No treatment & 21 (14.6) & $3(3.0)$ & $\begin{array}{c}1.63 \\
(1.00-2.65)\end{array}$ & 0.048 \\
\hline Prophylaxis & 67 (46.5) & 37 (36.6) & & \\
\hline ART & 56 (38.9) & $61(60.4)$ & & \\
\hline \multicolumn{5}{|c|}{ Time since diagnosis } \\
\hline$>1$ year & $68(47.6)$ & $23(22.3)$ & $\begin{array}{c}2.20 \\
(1.42-3.40)\end{array}$ & 0.000 \\
\hline 1 - 5 years & $69(48.6)$ & $58(56.3)$ & & \\
\hline $6-10$ years & $4(2.8)$ & 19 (18.5) & & \\
\hline$<10$ years & $2(1.4)$ & $3(2.9)$ & & \\
\hline \multicolumn{5}{|c|}{ Disclosure of HIV status to others } \\
\hline Not disclosed & $16(11.1)$ & $6(5.8)$ & $\begin{array}{c}1.07 \\
(0.92-1.25)\end{array}$ & 0.348 \\
\hline Disclosed & 128 (88.9) & 98 (94.2) & & \\
\hline
\end{tabular}

"OR: Crude Odds Ratio.
Table 4. Perceived barriers to participation in HIV support groups among attenders and non-attenders.

\begin{tabular}{lc}
\hline Why are you not participating in an HIV support groups & Frequency \\
\hline I have concerns about my privacy in a support group. & 73 \\
$\begin{array}{l}\text { I do not want people to know that I am HIV positive. } \\
\text { Support group meetings are hard to find in the area where I }\end{array}$ & 43 \\
live. & \\
$\begin{array}{l}\text { I do not know that support groups are available for HIV } \\
\text { positive people. }\end{array}$ & 33 \\
$\begin{array}{l}\text { My working hours prevents me from going to a support } \\
\text { group. }\end{array}$ & 54 \\
$\begin{array}{l}\text { I am not able to attend a support group because of my } \\
\text { illness. }\end{array}$ & 20 \\
$\begin{array}{l}\text { I do not like talking in a group. } \\
\text { I do not have transportation to and from a support group. }\end{array}$ & 38 \\
$\begin{array}{l}\text { My home schedule prevents me from going to a support } \\
\text { group. }\end{array}$ & 22 \\
\begin{tabular}{l} 
I do not need a support group right now. \\
\hline
\end{tabular}
\end{tabular}

*Participants gave more than one barrier to participate in support groups; therefore the numbers reported are more than the total $(n=248)$.

for a longer time than non-attenders [2,22]. We also found that participants who attended HIV support groups were significantly more likely to be taking HIV prophylaxis and ART medication than non-attenders. Since the introduction of HIV counselling and testing (HCT) in South Africa, more people test for HIV when they are still relatively healthy and need prophylaxis medication, care and support. One of the main barriers for attending HIV support groups was the participant's perception that they do not need support groups. A highly held perception of support groups by participants in this study was that support groups were for people who cannot cope with their HIV status, and seek love, support, and acceptance. Similar findings that support groups were for people who could not cope with HIV, were previously reported [2, 17].

The employment status of participants was also significantly associated with attending HIV support groups. Employed participants were significantly less likely to attended HIV support groups than unemployed participants. Attending support groups was not significantly associated with employment in a previous study [2]. Employment was cited as a barrier to participate in support groups. Participants indicated that their work prevent them from attending support groups because support groups are held during week days. Similarly, employed HIV positive men were unable to take time off to attend support groups meetings because they were given only one day off to collect ART medication [17]. In this study, unemployed participants also cited time as a barrier; their 
home schedule and health status did not allow them to attend support groups. Time was found to be a barrier to attending support group meetings in previous studies [6, 16-18].

Participants reported several other barriers that hinder attendance of support groups for PLWHI. The most common barriers were concerns about privacy in HIV support groups, and fear that people would know about their HIV positive status. In addition, slightly more than a quarter (26\%) of the participants did not attend support groups for fear of being stigmatized. Qualitative study conducted in South Africa also found that participants perceived support groups as lacking confidentiality. Consequently, participants preferred not to attend support groups in their local communities for fear of being recognised as HIV positive. Participants were fearful that if their status is known, they would be stigmatized and socially rejected [17]. Lack of transport money and distance were also reported as barriers to attend support groups in this study. The barriers to attend support groups from this study should be viewed in the context that the majority of the participants had never attended any support group and did not personally experience some of the barriers, with the exception that support groups are hard to find. Similarly, Walch et al. [22] reported that participants who had never attended support groups reported more perceived barriers to participation than those who had previously attended support groups.

Disclosure of the HIV status is inevitable in support groups, and individuals may fear the possible discrimination following disclosure in support groups [14]. The fear of stigma and discrimination influences the intentions for future participation in support groups. Madiba and CantiSigaqa [17] reported that participants preferred to receive HIV treatment, care and support from health facilities far from their communities. They feared that they would be stigmatized and discriminated if they attend health care facilities in their communities. Concerns about confidentiality were also reported in other studies. Participants were concerned that their attendance of the support group would reveal their HIV status to other people they would prefer not to know [18]. Confidentiality was also reported as a barrier among participants of a hospital based support group. They were concerned about the large support group size and the open nature of the support group which prevented them from opening up and sharing their experiences [19]. In this study, a high proportion (76\%) of participants would also prefer to attend small sized support groups for similar concerns.

This study revealed that $91 \%$ of the respondents had disclosed their HIV status to other people; $60 \%$ of participants disclosed to partners and friends. Though partners and friends were the most common person disclosed to, slightly less than a quarter of the participants also disclosed to parents. Similar to earlier findings, there were no differences in terms of the numbers of people support group attenders and non-attenders disclosed to [2]. In this study, disclosure was not significantly associated with HIV support group attendance. On the contrary, we found that participants believed that they did not need support groups. Similar findings were reported by Madiba and Canti-Sigaqa [17], HIV positive men in their study, perceived the support they received from their families adequate. All participants had disclosed their HIV status to partners and families. Previous studies show close association between disclosure and perceived social support, and that PLWHI who disclose to family enjoy greater social support than non-disclosed people [24-26].

The study is limited in that the majority of participants attended between 1 - 2 support group meetings only, therefore, the perceptions of HIV positive people who attend support groups are under represented here. In addition, the study did not establish the reasons participants who previously attended support groups stopped attending. The study also relied on self-reported data on the attendance and non-attendance of support groups, responses are subject to social desirability bias which may lead to overestimation of attendance of support groups. The strength of the study is the relatively large sample size representing HIV positive people in HIV facilities in Gauteng province. Even though the findings may not be generalized to the country, they have implications for interventions with PLWHI.

\section{Conclusions}

The study found that more than half of the participants had never attended support groups. Attendance of support groups was associated with age, employment status, time since diagnosis, and ART status.

Concerns for privacy and confidentiality were the key barriers to participate in support groups, and a high proportion of participants believed that they did not need support groups. The data suggest that stigma and discrimination is a key barrier to access care and support for PLWHI. This finding has implications for the provision of care and support for HIV positive people. Health care providers who plan to start support groups should take into consideration issues of group size, confidentiality, and timing for group meetings.

Participants also perceived support groups as a service for people who cannot cope with their HIV diagnosis. Health care providers have a critical role to play in creating awareness of and education on the benefits of support groups for PLWHI at the time of diagnosis and on each follow up for ART medication. 
It is also recommended that support groups should be designed in a way that they allow PLWHI to exit when they have been empowered to manage their HIV diagnosis. With people surviving longer and experiencing good health while on ART, it would be more acceptable for newly diagnosed people that membership of support groups is not for lifetime.

\section{REFERENCES}

[1] L. C. Simbayi, "HIV, Stigma, and Psychotherapy,” Conference on Psychotherapy, Vol. 18, 2008, p. 20.

[2] S. C. Kalichman and K. J. Sikkema, "People Living with HIV Infection Who Attend and Do Not Attend Support Groups: A Pilot Study of Needs, Characteristics and Experiences,” AIDS Care, Vol. 8, No. 5, 1996, pp. 589-600. doi:10.1080/09540129650125542

[3] R. Spirig, "Support Groups for People Living with HIV/ AIDS: A Review of Literature," Journal of the Association of Nurses in AIDS Care, Vol. 9, No. 4, 1998, pp. 4355. doi:10.1016/S1055-3290(98)80044-7

[4] WHO, "Psychosocial Support,” WHO HIV Topics, 2004. http://www.who.int/hiv/topics/psychosocial/support/en/

[5] N. VanDevanter, N. S. Parikh, R. M. Cohall, C. Merzel, N. Faber, et al., "Factors Influencing Participation in Weekly Support Groups among Women Completing an HIV/ STD Intervention Program," Women \& Health, Vol. 30, No. 1, 2000, pp. 15-34. doi:10.1300/J013v30n01_02

[6] M. J. Visser and J. P. Mundell, "Establishing Support groups for HIV-Infected Women: Using Experiences to Develop Guiding Principles for Project Implementation,” SAHARA-J: Journal of Social Aspects of HIV/AIDS, Vol. 5, No. 2, 2008, pp. 65-73. doi:10.1080/17290376.2008.9724903

[7] S. A. Wood, "The Analysis of an Innovative HIV-Positive Women's Support Group,” Social Work with Groups, Vol. 30, No. 3, 2007, pp. 9-28. doi:10.1300/J009v30n03_02

[8] M. Visser, J. Mundell, A. de Villiers, K. Sikkema and B. Jeffery, "Development of Structured Support Groups for HIV-Positive Women in South Africa," SAHARA-J: Journal of Social Aspects of HIV/AIDS, Vol. 2, No. 3, 2005, pp. 333-343.

[9] R. Lennon-Dearing, "The Benefits of Women-Only HIV Support Groups,” Journal of HIV/AIDS \& Social Services, Vol. 7, No. 1, 2008, pp. 27-45. doi:10.1080/15381500802093142

[10] S. Kalichman, D. Rompa and M. Cage, “Group Intervention to Reduce HIV Transmission Risk Behavior among Persons Living with HIV-AIDS,” Behavior Modification, Vol. 29, No. 2, 2005, pp. 256-285. doi:10.1177/0145445504272603

[11] M. Chazan, "Understanding Community Mobilization around HIV/AIDS in South Africa: A Preliminary Scoping Study: Health Economics \& HIV/AIDS Research Division (HEARD)," University of Natal, 2006.

http://www.heard.org.za/downloads/chazan-community- mobilisation-full-report-working-paper-sep-2006.pdf

[12] E. Shacham, M. Reece, W. Ong'or, O. Omollo, P. O. Monahan, et al., "Characteristics of Psychosocial Support Seeking during HIV-Related Treatment in Western Kenya," AIDS Patient Care \& STDs, Vol. 2, No. 7, 2008, pp. 595601. doi:10.1089/apc.2007.0213

[13] P. Maboshe, "Living with HIV/AIDS in Rural/Remote Communities of Western Zambia Province,” XVII International AIDS Conference, 2008, Abstract no CDD0545.

[14] J. P. Mundell, M. J. Visser, J. D. Makin, T. S. Kershaw, B. W. C. Forsyth, et al., "The Impact of Structured Support Groups for Pregnant South African Women Recently Diagnosed HIV Positive,” Women \& Health, Vol. 51, No. 6, 2011, pp. 546-565. doi:10.1080/03630242.2011.606356

[15] K. L. Sandstrom, "Searching for Information, Understanding, and Self-Value," Social Work in Health Care, Vol. 23, No. 4, 1996, pp. 51-74. doi:10.1300/J010v23n04_05

[16] P. Liamputtong, N. Haritavorn and N. Kiatying-Angsulee, "HIV and AIDS, Stigma and AIDS Support Groups: Perspectives from Women Living with HIV and AIDS in Central Thailand,” Social Science \& Medicine, Vol. 69, No. 6, 2009, pp. 862-868.

doi:10.1016/j.socscimed.2009.05.040

[17] S. Madiba and V. Canti-Sigaqa, "Barriers to Participate in Support Groups for People Living with HIV: A Qualitative Study with Men Receiving Antiretroviral Treatment in a HIV Clinic in Mthatha, South Africa," Global Journal of Health Science, Vol. 4, No. 6, 2012, pp. 119-127. doi:10.5539/gjhs.v4n6p119

[18] K. Morrow, T. Costello and T. Boland, "Understanding the Psychosocial Needs of HIV-Positive Women: A Qualitative Study,” Psychosomatics, Vol. 42, No. 6, 2001, pp. 497-503. doi:10.1176/appi.psy.42.6.497

[19] A. Heyer, H. Mabuza, I. C. Couper and G. A. Ogunbanjo, "Understanding Participation in a Hospital-Based HIV Support Group in Limpopo Province, South Africa,” South African Family Practice, Vol. 52, No. 3, 2010, pp. 234 239.

[20] L. Gilbert and L. Walker, "My Biggest Fear Was That People Would Reject Me Once They Knew My Status...: Stigma as Experienced by Patients in an HIV/AIDS Clinic in Johannesburg, South Africa," Health \& Social Care in the Community, Vol. 18, No. 2, 2010, pp. 139-146. doi:10.1111/j.1365-2524.2009.00881.x

[21] S. W. Mak, C. Poon, L. Pun and S. Cheung, "MetaAnalysis of Stigma and Mental Health,” Social Science \& Medicine, Vol. 65, No. 2, 2007, pp. 245-261. doi:10.1016/j.socscimed.2007.03.015

[22] S. C. Walch, L. M. Roetzer and T. A. Minnett, "Support Group Participation among Persons with HIV: Demographic Characteristics and Perceived Barriers," AIDS Care: Psychological and Socio-Medical Aspects of AIDS/HIV, Vol.18, No. 4, 2006, pp. 284-289.

[23] StataCorp, “Stata Statistical Software. Release 10,” StataCorp LP, TX, 2007.

[24] C. A. Emlet, "An Examination of the Social Networks and Social Isolation in Older and Younger Adults Living with HIV/AIDS,” Health and Social Work, Vol. 31, No. 4, 
2006, pp. 299-308. doi:10.1093/hsw/31.4.299

[25] S. C. Kalichman, M. DiMarco, J. Austin, W. Luke and K. DiFonzo, "Stress, Social Support, and HIV-Status Disclosure to Family and Friends Among HIV-Positive Men and Women,” Journal of Behavioral Medicine, Vol. 26,
No. 4, 2003, pp. 315-332. doi:10.1023/A:1024252926930

[26] J. M. Serovich, P. S. Brucker and J. A. Kimberly, "Barriers to Social Support for Persons Living with HIV/ AIDS,” AIDS Care, Vol. 12, No. 5, 2000, pp. 651-662. doi:10.1080/095401200750003824 